\title{
Pembangunan Sistem Informasi Pengelolaan Alat Dan Bahan Praktek Pada Politeknik Pertanian Negeri Payakumbuh
}

\author{
Camelia Radhyani*1, Ravi Ahmad Salim², Amrizal ${ }^{3}$ \\ ${ }^{1,2}$ Jurusan Sistem Informasi Bisnis, Program Magister Manajemen Sistem Informasi, \\ Universitas Gunadarma, Jalan Kenari I, Kenari, Kec. Senen, Kota Jakarta Pusat, DKI Jakarta, \\ Tlp (021) 31930220 \\ ${ }^{3}$ Teknologi Pertanian, Politeknik Pertanian Negeri Payakumbuh,Tanjung Pati,Kabupaten 5o \\ Kota, Sumatera Barat, Tlp (0752) 7754192 \\ Email: cameliaradhyani@ymail.com*,1, Ravisalim@gmail.com², amrizal.ch@gmail.com ${ }^{3}$
}

\begin{abstract}
Abstrak
Perkembangan teknologi informasi telah menjamah proses dalam ruang lingkup universitas agar dapat meningkatkan efektifitas dan efisiensi kerja. Salah satu contoh adalah untuk pengelolaan alat pada kampus Politeknik Pertanian Negeri Payakumbuh yang kurang efisien karena masih menerapkan sistem yang manual. Politeknik Pertanian Negeri Payakumbuh adalah pendidikan Vokasional dimana $70 \%$ nya adalah pertemuannya meliputi praktek / labor, sehingga alat dan bahan cukup tinggi untuk setiap mata kuliah. Kebutuhan alat dan bahan diajukan setiap semester sebelum perkuliahan oleh semua Dosen penangung jawab mata kuliah. Pengajuan kebutuhan alat dan bahan tersebut berupa jenis / bahan, jumlah alat / bahan, digunakan pada pertemuan keberapa, lokasi / labor kompetensi. Dengan menggunakan sistem manual yang berjalan pada saat ini masih terasa kurang efisien dalam pengelolaannya. Untuk itu sangat diperlukan sebuah sistem informasi untuk mempermudah pengajuan alat dan bahan praktek. Proses Pembuatan Sistem Informasi ini memggunakan Metode Extreme Programing (XP). Extreme Programming (XP) dipilih karena perangkat lunak yang akan dibuat tidak terlalu kompleks dan tergolong perangkat lunak berskala kecil dan juga membutuhkan waktu pengembangan yang tidak terlalu lama. Dimana Tahapan dari metode ini terdiri dari Panning, Design, Coding, Testing. Hasil dari Pembangunan Sistem Informasi pengelolaan Alat dan Bahan praktek ini nantinya merupakan sebuah Aplikasi yang akan membantu mempercepat proses pengajuan Alat dan Bahan Praktek. Aplikasi tersebut dibuat dengan bahasa pemrograman $P H P$ dan Databasenya MySQL. Sedangkan untuk frameworknya menggunakan Codeigniter dan Bootstrap.
\end{abstract}

Kata kunci: Extreme Programing, PHP, MySQL, Codeigniter, Bootsrap

\begin{abstract}
The development of information technology has touched the process within the scope of the university in order to improve the effectiveness and efficiency of work. One of the examples is the management tool at State Agricultural Polytechnic of Payakumbuh which is less efficient due to applying a manual system. State Agricultural Polytechnic of Payakumbuh is Vocational education of which has the meeting of $70 \%$ practice, the equipment and material requirements are submitted every semester by the supervisor before the lecture begins. Submission the equipment and material requirements are types/materials, the number of tools/materials, used at the meeting keberapa, location/labor. By using the current manual system which is less efficient in the management requires an information system to facilitate the submission of tools and practice materials. The process of making this information system using the Method of Extreme
\end{abstract}


Programming $(X P)$. Extreme Programming $(X P)$ is selected due to the software that will be made less complex and is classified as small software and also requires short development time. Where Stages of this method is Panning, Design, Coding, Testing. Results of the Development of Information System for Tool Management and Practice Material will be an application that will help speed up the process of submitting Tools and Practice Materials. The application is made with the programming language $P H P$ and the database is MySQL. While for framework using CodeIgniter and Bootstrap.

Keywords: Extreme Programming, PHP, MySQL, Codeigniter, Bootstrap

\section{PENDAHULUAN}

Sistem Informasi merupakan konsep yang luas dari sebuah sistem yang tunggal. Beberapa aktifitasi dari sistem informasi adalah keterpaduan dengan pengolahan data harian, sementara aplikasi-aplikasi sistem informasi dirancang untuk mengetahui pekerjaan atau fungsi untuk pengambilan keputusan. Rancangan dari sistem informasi dalam sebuah organisasi mengharuskan mengidentifikasi kepreluan informasi. Sistem informasi merupakan salah satu hal terpenting dalam suatu perusahaan. Dengan adanya sistem informasi maka organisasi atau perusahaan dapat menjamin kualitas informasi yang disajikan dan dapat mengambil keputusan berdasarkan informasi tersebut [1].

Pada hakikatnya suatu sistem mempunyai karakteristik atau sifat-sifat tertentu, yaitu mempunyai komponen-komponen (component), batasan sistem (boundary),lingkungan luar sistem (environment), penghubung sistem (interface), masukan sistem (input), pengolahan sistem (process), keluaran sistem (output), dan sasaran sistem (objectives) atau tujuan sistem (goal) [5]. Seiring perkembangan teknologi maka kebutuhan akan informasi yang cepat, tepat dan akurat sangat diperlukan. Perancangan merupakan suatu kegiatan yang memiliki tujuan untuk membuat sistem baru melalui teknik tersebut dapat tercipta sebuah sistem terstruktur, sehungga dapat menghasilkan sistem dengan kinerja yang diharapkan [9].

Majunya perkembangan Teknologi informasi sudah mencapai taraf sebagai kebutuhan, sehingga semua lapisan masyarakat termasuk mahasiswa, Dosen, dan Staff perguruan tinggi tergerak untuk maju dan menggunakannya. Perkembangan teknologi informasi juga menjamah proses dalam ruang lingkup universitas agar dapat meningkatkan efektifitas dan efisiensi kerja. Salah satu contoh adalah untuk pengelolaan alat pada kampus Politeknik Pertanian Negeri Payakumbuh yang kurang efisien karena masih menerapkan sistem yang manual. Dengan menggunakan sistem manual yang berjalan pada saat ini masih terasa kurang efisien dalam pengelolaannya. Tujuan dari Penelitian ini diantaranya untuk merancang sistem informasi pengelolaan alat dan bahan yang digunakan untuk menunjang proses perkuliahan, untuk merancang sebuah sistem informasi yang mampu menginventarisir penggunaan serta peminjaman alat dan bahan.

\section{METODE PENELITIAN}

Objek penelitian ini mengambil data dari rekap pengelolaan alat dan bahan untuk proses perkuliahan yang telah ada sebelumnya kemudian di olah agar bisa di buat kedalam sebuah aplikasi. Penelitian ini dilakukan dengan mengambil objek dari beberapa jurusan dikampus Politeknik Pertanian Negeri Payakumbuh.

Penulis menggunakan sumber data untuk mendukung penelitian dalam menyelesaikan jurnal ini. Data yang masih merupakan bahan mentah apabila tidak diolah maka datatersebut

Radhyani, et., al [Pembangunan Sistem Informasi Pengelolaan Alat dan Bahan Praktek pada Politeknik Pertanian Negeri Payakumbuh] 
tidak berguna. Data tersebut akan berguna dan menghasilkan suatuinformasi apabila diolah melalui suatu model. Model yang digunakan untukmengolah data tersebut disebut dengan model pengolahan data atau lebih dikenaldengan nama siklus pengolahan data [2].

Sumber datanya meliputi "Data primer". Adapun definisi dan contoh data yang diambil dari objek penelitian. Data Primer ini diambil / diperoleh secara langsung dari sumber asli. Data jenis ini diperoleh dari hasil survey dan hasil wawancara dengan Dosen di Politeknik Pertanian Negeri Payakumbuh.

Teknik pengumpulan data merupakan langkah yang paling utama dalam penelitian, karena tujuan utama dari penelitian adalah mendapatkan data. Tanpa mengetahui teknik pengumpulan data, maka peneliti tidak akan mendapatkan data yang memenuhi standart yang ditetapkan . Dalam peneliti ini, pengumpulan data dilakukan pada natural setting (kondisi yang alamiah), sumber data primer, dan teknik pengumpulan data lebih banyak pada observasi berperan serta (participation observation), wawancara mendalam (in dept interview) dan dokumentasi.

1. Observasi

Observasi merupakan metode pengumpulan data yang dilakukan dengan cara mengamati dan mencatat secara sistematik terhadap gejala-gejala yang diselidiki. Jika suatu data yang diperoleh kurang meyakinkan,biasanya peneliti akan menanyakan kepada subyek secara langsung,tetapi karena ia hendak memperoleh keyakinan terhadap keabsahan data tersebut jalan yang ditempuh adalah mengamati sendiri berarti mengalami langsung peristiwa nya. Pengamatan (observasi) merupakan metode pengumpulan di mana penelitian atau kolaboratornya mencatat informasi sebagaimana yang mereka saksikan selama penelitian.

\section{Wawancara}

Wawancara adalah suatu bentuk komunikasi verbal jadi semacam percakapan yang bertujuan memperoleh informasi langsung dari narasumber yang bersangkutan. Wawancara yaitu metodepengumpulan data yang menggunakan pedoman berupa pertayaaan yang diajukan langsung kepada obyek untuk mendapatkan respon secara langsung. Wawancara merupakan metode kedua yang digunakan dalam penelitian untuk memahami bagaimana masyarakat memandang, mejelaskan dan menggambarkan tata hidup mereka sendiri (ethnometodologik). Adapun jenis wawancara yang digunakan dalam penelitian ini adalah wawancara bebas terpimpin atau semi terstruktur, yakni penulis menyiapkan kerang kapertayaan sebelum wawancara, hanya saja dalam pelaksanaanya lebih bebas bila dibandingkan wawancara terstruktur.

Pendekatan metode pengembangan sistem yang digunakan peneliti merupakan salah satu dari agile methods yaitu EXtreme Programming (XP). Extreme Programming (XP) dipilih karena perangkat lunak yang akan dibuat tidak terlalu kompleks dan tergolong perangkat lunak berskala kecil dan juga membutuhkan waktu pengembangan yang tidak terlalu lama. Dalam metode ini terdapat 4 tahap pengerjaannya yaitu Planning, Design, Coding, Testing.

\section{Planning}

Dalam tahap ini dikumpulkan kebutuhan awal user atau dalam XP disebut user stories. Hal ini dibutuhkan agar pengembang mengerti bisnis konten, kebutuhan output sistem, dan fitur utama dari software yang dikembangkan [7].

\section{Design}

Desain dari system pada penelitian ini digambarkan dengan model UML berupa use case diagram, activity diagram, dan relation table [3]. Pembuatan desain pada XP tetap mengedepankan prinsip Keep it Simple (KIS). Desain disini merupakan representasi dari system guna mempermudah pengembang dalam membangun system.

Radhyani, et., al [Pembangunan Sistem Informasi Pengelolaan Alat dan Bahan Praktek pada Politeknik Pertanian Negeri Payakumbuh] 


\section{Coding}

Pada tahap ini dibangun sebuah Sistem Informasi Pengelolaan alat dan bahan praktek yang menjadi objek penelitian [8]. Sistem dibangun berdasarkan desain yang telah dibuat pada tahap sebelumnya. Dalam pembangunan system ini menggunakan bahasa pemrograman PHP, HTML, dan MySQL [6]. Bahasa pemrograman tersebut didukung oleh software Codeigniter (CI) [10]. Pada tahap coding juga disisipkan tahap refactoring. Refactoring adalah proses mengubah system perangkat lunak sedemikian rupa dengan tidak mengubah eksternal kode dalam memperbaiki struktur internalnya[4]. Hal ini dilakukan untuk meminimalkan kemungkinan adanya bug.

\section{Testing}

Pada tahap ini sistem yang telah dibangun dicoba apakah kebutuhan awal user atau user stories sudah dipenuhi dan apabila terpenuhi software siap dirilis.

Pendekatan metode pengembangan sistem yang digunakan peneliti merupakan salah satu dari agile methods yaitu EXtreme Programming (XP). Extreme Programming (XP) dipilih karena perangkat lunak yang akan dibuat tidak terlalu kompleks dan tergolong perangkat lunak berskala kecil dan juga membutuhkan waktu pengembangan yang tidak terlalu lama.

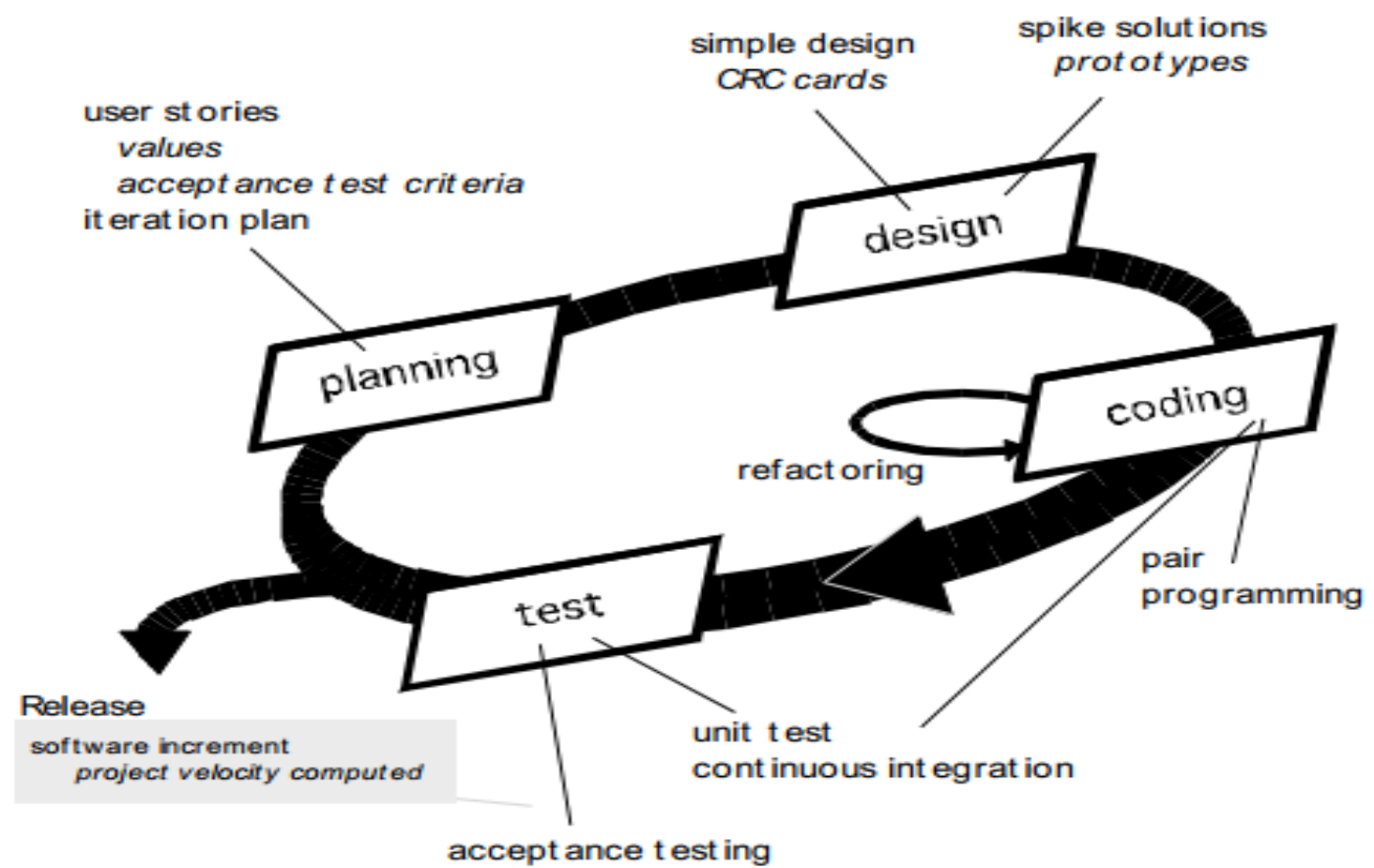

Gambar 1. Skema Metode Extreme Programming

\section{Analisis Sistem Berjalan}

Saat ini sistem manual yang sedang berjalan membutuhakn waktu yang sangat lama. Dimana dalam prosesnya bisa membutuhkan waktu berbulan - bulan, dikarenakan sering terjadinya pending pada tiap tahapannya. Adapun proses berjalannya system saat ini sebagai berikut :

1. Masing - masing dosen penanggung jawab mata kuliah mengajukan kebutuhan alat dan bahan yang akan digunakan pada semester yang akan berjalan (pengajuan paling lama 2 minggu sebelum perkuliaahan dimulai).

2. Data ajuan yang dibuat dosen tersebut di kumpulkan ke ketua Program Studi.

Radhyani, et., al [Pembangunan Sistem Informasi Pengelolaan Alat dan Bahan Praktek pada Politeknik Pertanian Negeri Payakumbuh] 
3. Ketua Program studi merekap kebutuhan alat dan bahan tersebut, (berdasarkan labor yang akan digunakan), selanjutnya menyerahkan ke ketua Labor kompetensi.

4. Masing - masing kepala labor kompetensi merekap semua data yang masuk dari semua ketua Program studi dan selanjutnya diserahkan ke wakil direktur 1 (Bidang Akademik).

5. Wakil Direktur 1 akan melakukan Rekapitulasi untuk selanjutnya di serahkan ke wadir 2 (Bidang Keuangan).

6. Wakil Direktur 2 akan merekap dan selanjutnya diserahkan ke bagian pengadaan barang sesuai kebutuhan.

7. Barang yang sudah ada akan didistribusikan ke labor kompetensi yang membutuhkan sesuai dengan permintaan awal.

8. Selanjutnya dosen akan menggunakan Alat / Bahan yang sudah tersedia di Labor untuk proses perkuliahan/praktikum.

\section{HASIL DAN PEMBAHASAN}

Untuk gambaran alur sistem yang diusulkan penulis merancang dengan menggunakan Flow Map yang menggambarkan secara Grafik langkah-langkah dan urutan prosedur, dan juga menganalisis dalam membantu pengoperasian sistem yang sedang dibangun, yang mana dapat dilihat pada gambar berikut: 


Dosen Penjab Ketua Prodi Labor Kompetensi Wadir I Wadir II Pengadaan

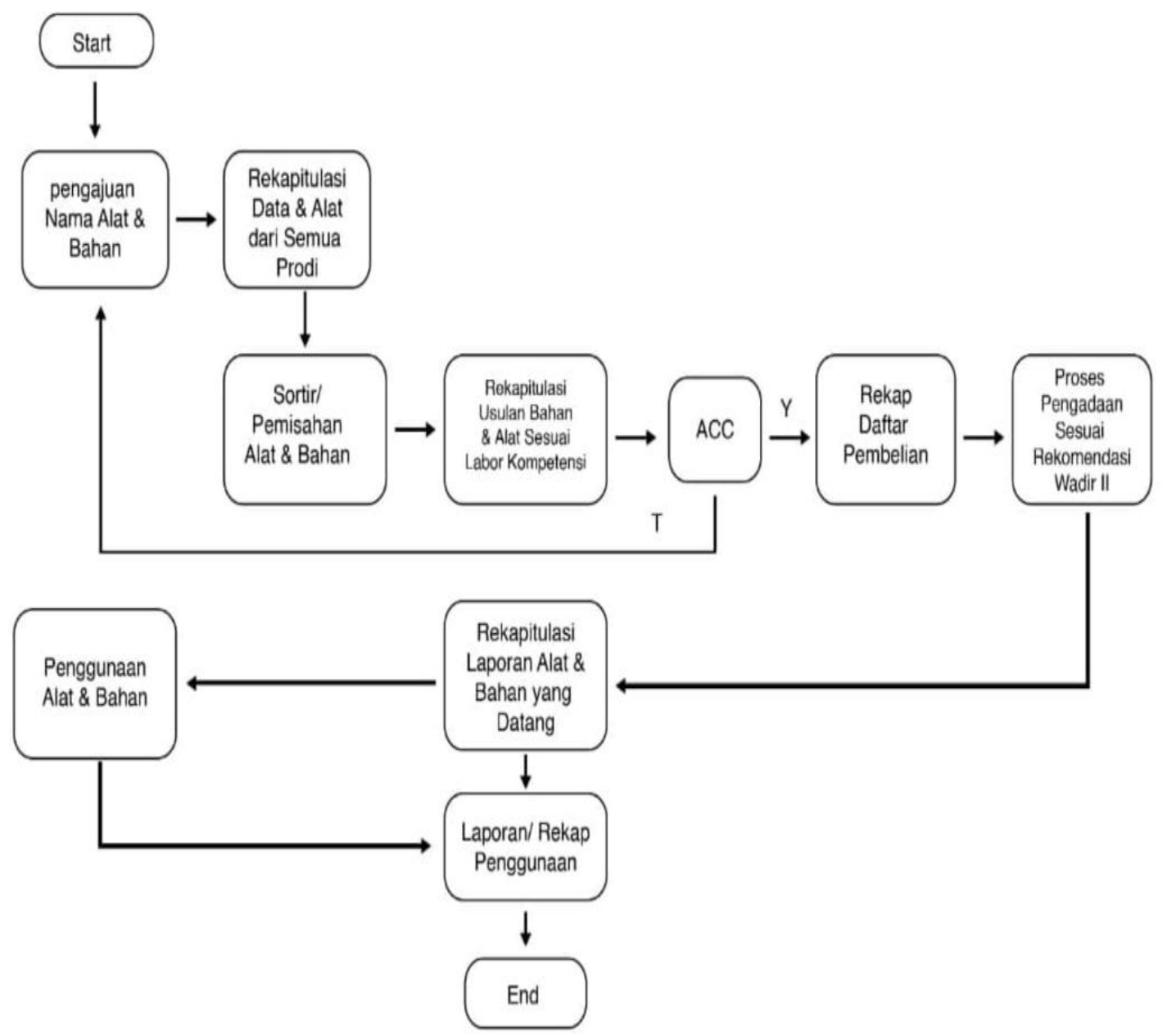

Gambar 2. Flow Map Alur Sistem yang Sedang Bejalan 
A. Use Case Diagram

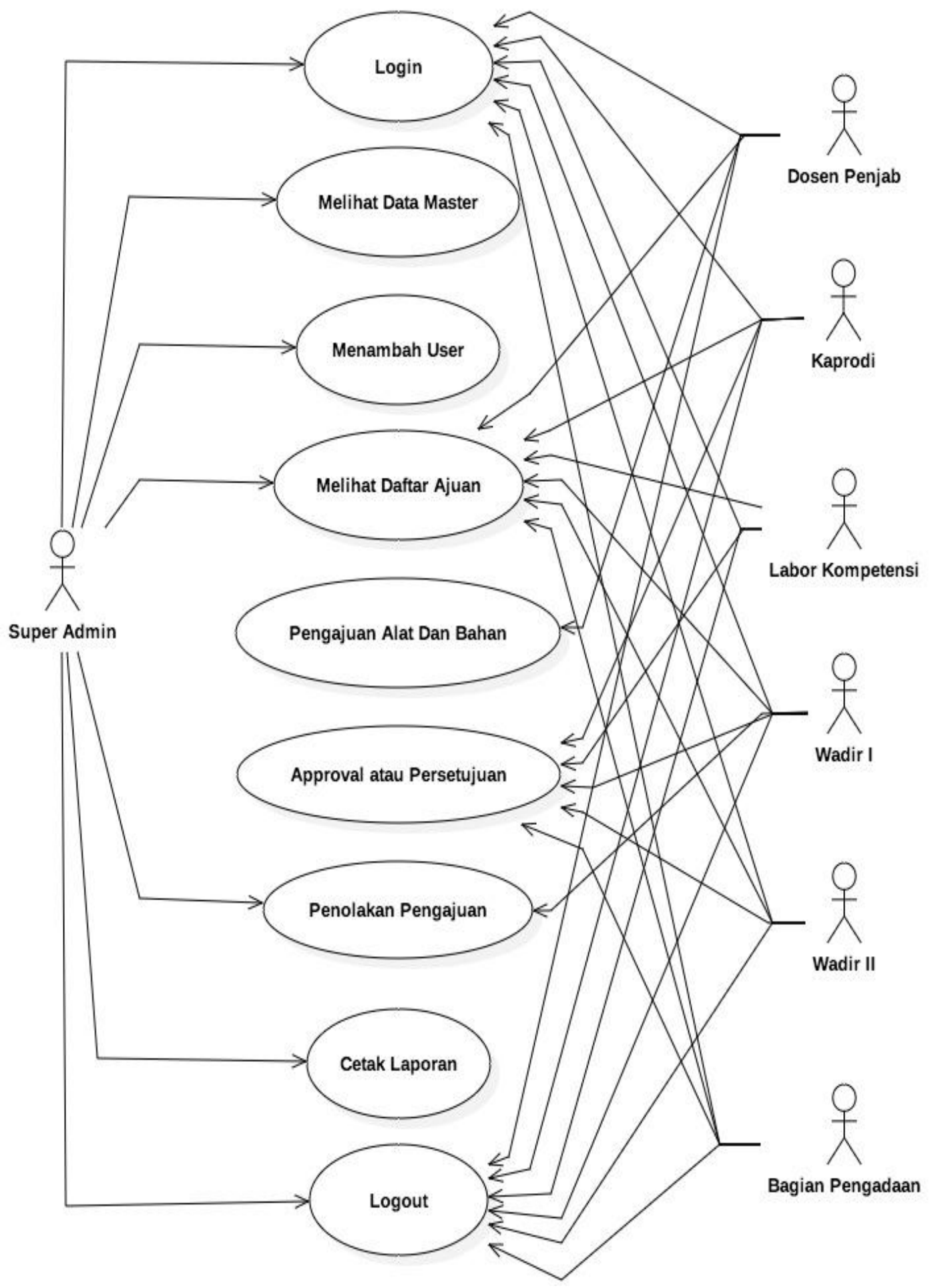

Gambar 3. Use Case Diagram Alur Sistem yang Diusulkan

Radhyani, et., al [Pembangunan Sistem Informasi Pengelolaan Alat dan Bahan Praktek pada Politeknik Pertanian Negeri Payakumbuh] 
Pada gambar diatas menjelaskan tentang alur sistem yang diusulkan untuk pengelolaan alat dan bahan praktek pada Politeknik Pertanian Negeri Payakumbuh dimulai dari Login, melihat data master, menambah user, melihat daftar ajuan, pengajuan alat dan bahan, approval / persetujuan, penolakan pengajuan, mencetak laporan dan logout.

B. Class Diagram
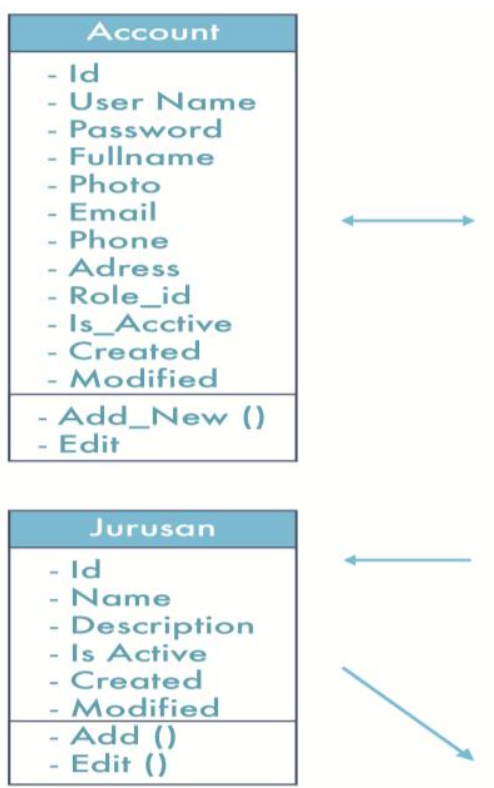

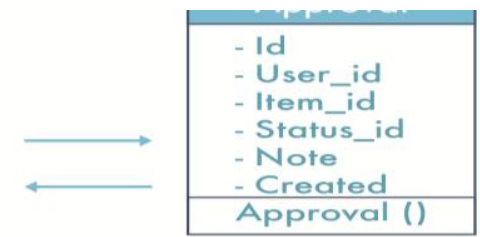

- User_id

Nomor

Mahasiswa

Topik_kegiatan

Tanggal

Jam

Laboratorium

Jenis kegiatan

Status_id

Created

Modified - Add () - Update ()

Expert ()

Add_detail ()
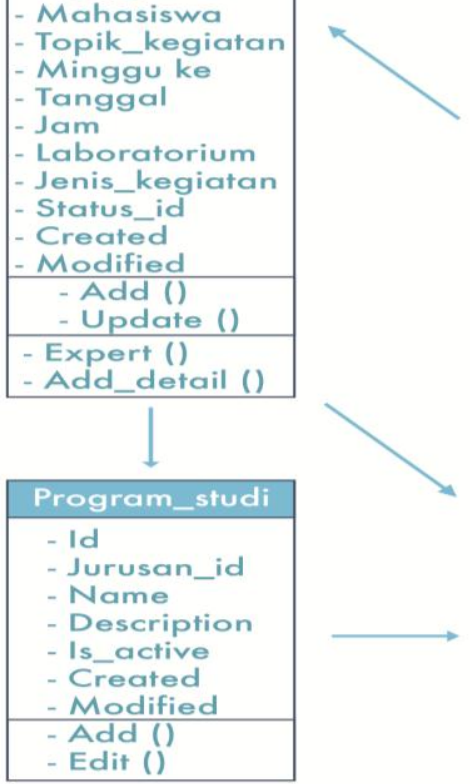

Pengajuan_detail

\section{- Id}

- Item_id

Jenis_id

Nama_barang

Spesifikasi

Satuan

- Jumlah

Harga

Kode

Is_active

Created

- Modified

Add ()

- Delete ()

\begin{tabular}{|l|}
\hline Mata_kuliah \\
\hline - Id \\
- Jurusan_id \\
- Prodi_id \\
- Name \\
- Description \\
- Is_active \\
- Created \\
- Modified \\
\hline - Add () \\
- Edit () \\
\hline
\end{tabular}

Gambar 4. Class Diagram Perancangan Sistem

\section{Component Diagram}

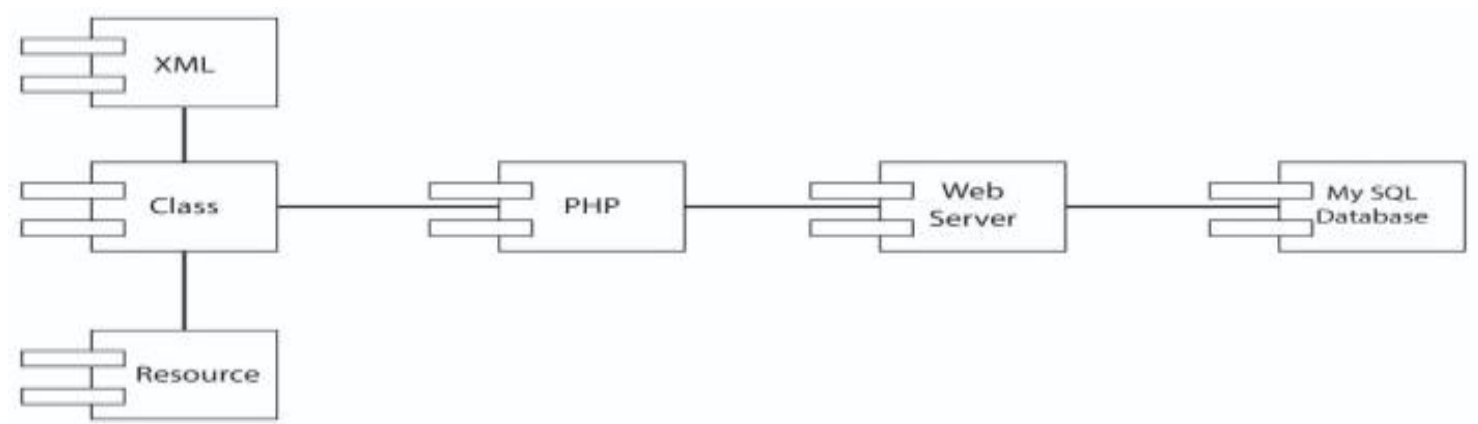

Gambar 5. Component Diagram Sistem Baru 
D. Perancangan Arsitektur Jaringan

Adapun kebutuhan untuk mendukung jaringan ini adalah:

1. User, pengguna yang memakai aplikasi.

2. Internet, untuk akses memperoleh database fasilitas umum.

3. Server, penyimpanan database informasi Fasilitas umum .

E. Implementasi Antar Muka

1. Menu Login

Merupakan tampilan dimana setiap user akan memulai untuk Login agar bias masuk ke account masing-masing.

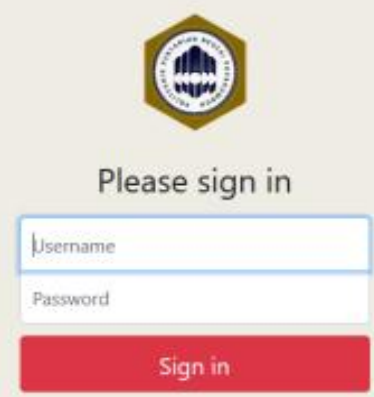

Gambar 6. Tampilan Awal Menu Login

2. Halaman Utama

Pada halaman ini menampilkan semua menu dan submenu pada aplikasi pengelolaan alat dan bahan praktek.

\section{$\Theta$ Politani Payakumbuh}

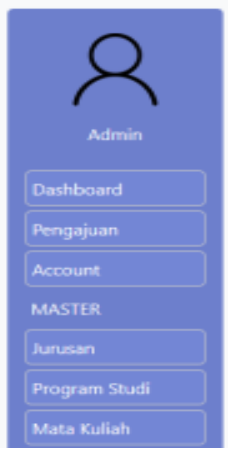

Welcome Admin

Recent updates

Gambar 7. Tampilan Halaman Utama

\section{Menu Pengajuan}

Pada halaman ini dosen penanggung jawab nantinya akan mengisi form pengajuan alat dan bahan praktek secara detail, dan nantinya akan diteruskan ke ketua program studi. 
$\Theta$ Politani Payakumbuh

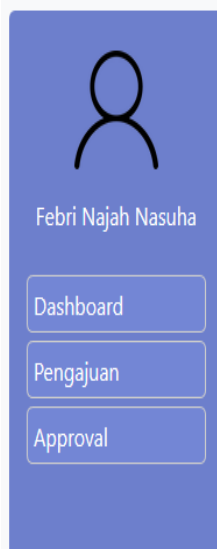

\begin{tabular}{|c|c|c|c|c|c|c|c|c|c|c|c|}
\hline Add New & \multicolumn{2}{|c|}{ Refresh } & Export Excel & & & & & & & & \\
\hline Show 10 & $\hat{\sim}$ & entries & & & & & & \multicolumn{4}{|c|}{ Search: } \\
\hline Jurusan & $\uparrow$ & Progr & am Studi & $\begin{array}{l}\text { Mata } \\
\text { Kuliah }\end{array}$ & Year $1 \downarrow$ & Semester $\uparrow \downarrow$ & Week $\uparrow \downarrow$ & Last Status & Created & 11 & 11 \\
\hline \multicolumn{2}{|l|}{$\begin{array}{l}\text { Teknologi } \\
\text { Pertanian }\end{array}$} & \multicolumn{2}{|c|}{$\begin{array}{l}\text { Teknologi Mekanisasi } \\
\text { Pertanian }\end{array}$} & $\begin{array}{l}\text { mata kuliah } \\
1\end{array}$ & 2020 & ganjil & 1 & $\begin{array}{l}\text { Rekapitulasi barang yang } \\
\text { sudah dipakai }\end{array}$ & \multicolumn{2}{|l|}{$\begin{array}{l}\text { 2020-01-05 } \\
15: 14: 57\end{array}$} & View \\
\hline Showing 1 & 010 & entr & & & & & & & Previous & 1 & Next \\
\hline
\end{tabular}

Gambar 8. Tampilan Menu Pengajuan

4. Detail Pengajuan

Pada halaman ini dosen penanggung jawab mengisi rincian yang lebih detail lagi mengenai alat dan bahan praktek yang dibutuhkan untuk proses perkuliahan.

\section{$\Theta$ Politani Payakumbuh}
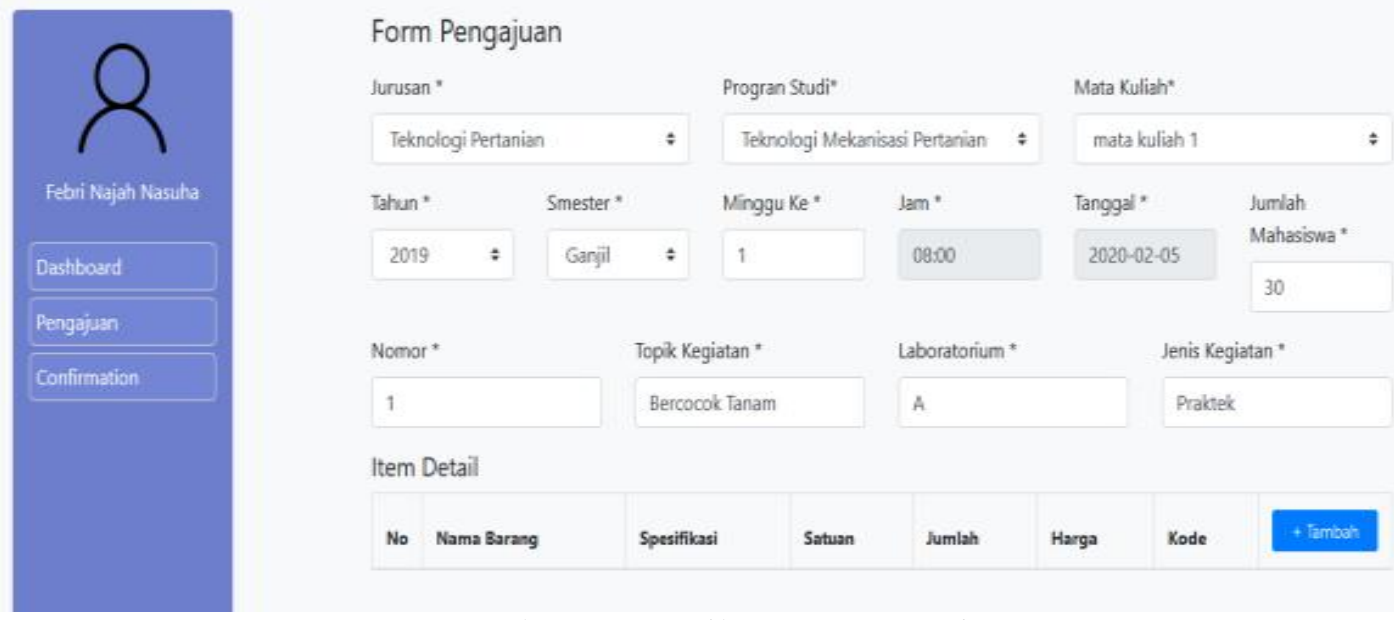

Gambar 9. Tampilan Form Pengajuan

5. Item Detai Pengajuan

Pada halaman ini dosen penanggung jawab mengisi lebih detail lagi tentang spesifikasi alat dan bahan yang di ajukan. 

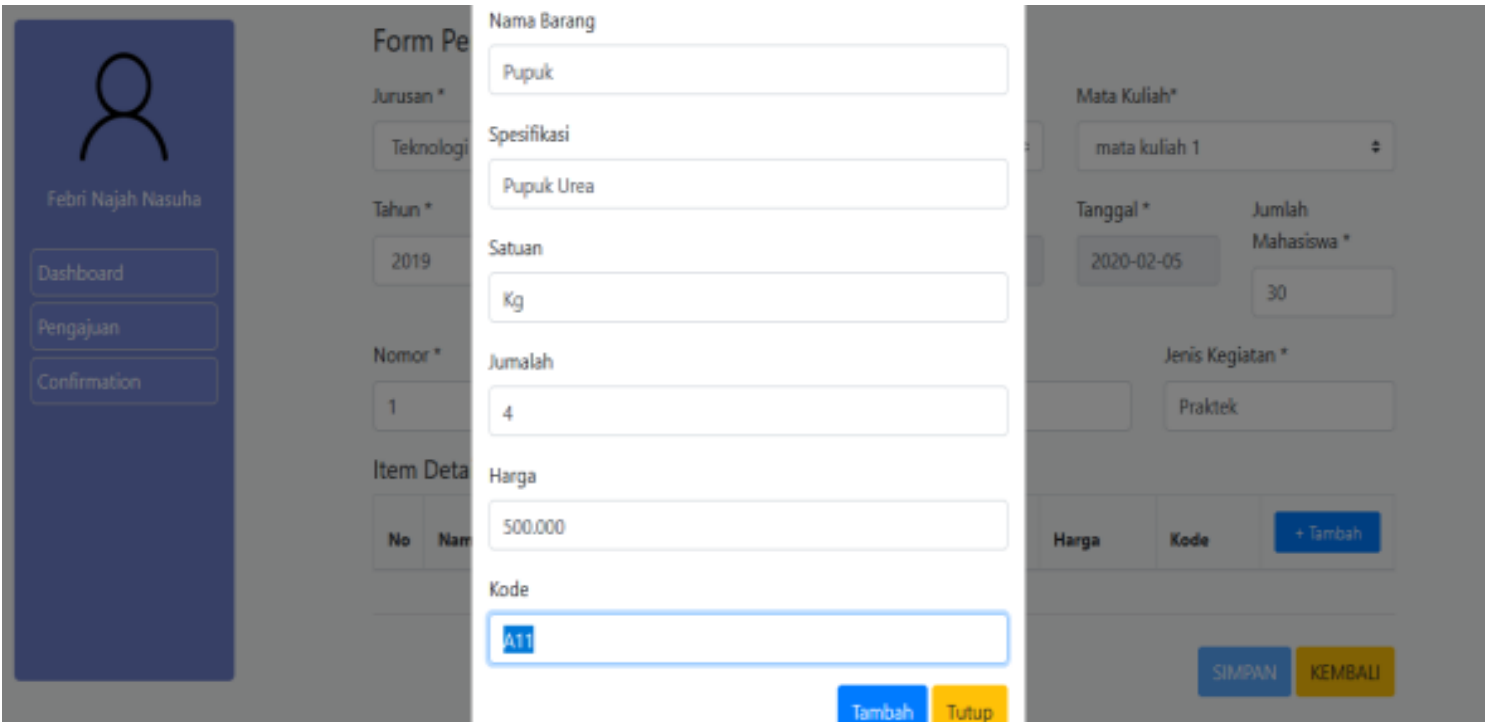

Gambar 10. Tampilan Detail Pengajuan

\section{List Approval}

Pada halaman ini akan menampilkan daftar ajuan alat dan bahan praktek yang telah di ajukan oleh dosen penanggung jawab yang nantinya akan di approve oleh Ketua Program Studi, Labor Kompetensi, Wakil Direktur I, Wakil Direktur II, dan bagian Pengadaan. Khusus untuk Wakil Direktur I (Wadir I) terdapat tombol Rejected,dikarenakan hanya pada Account ini yang memiliki wewenang untuk melakukan Reject.

a. Notifikasi Approval

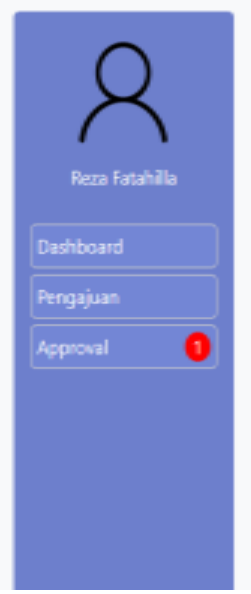

\section{Welcome Reza Fatahilla}

Recent updates

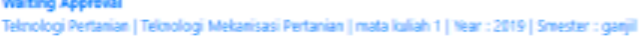

Gambar 11. Tampilan Notifikasi Approval 
b. List Approval

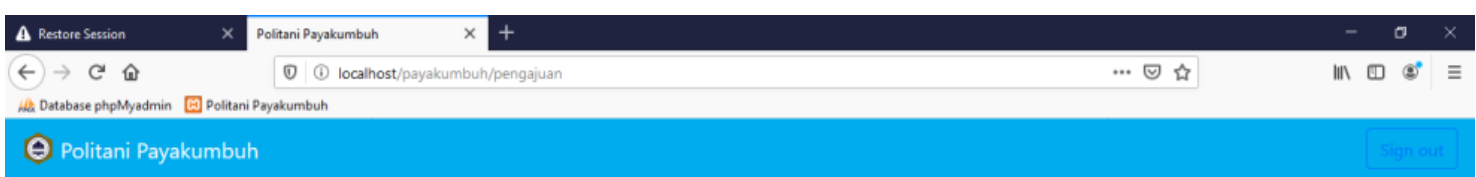
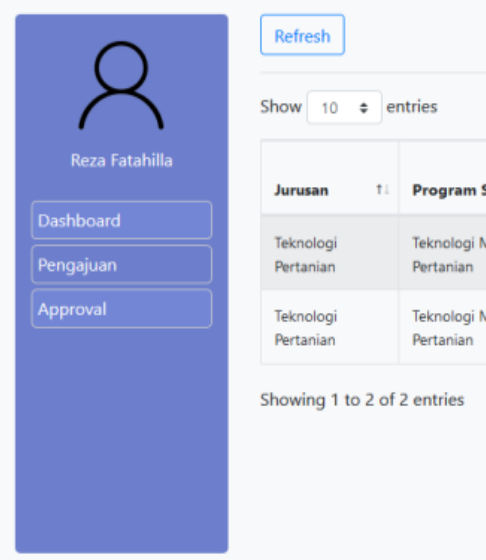

O Type here to search

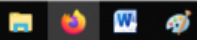

Gambar 12. Tampilan List Approval

c. Form Approval

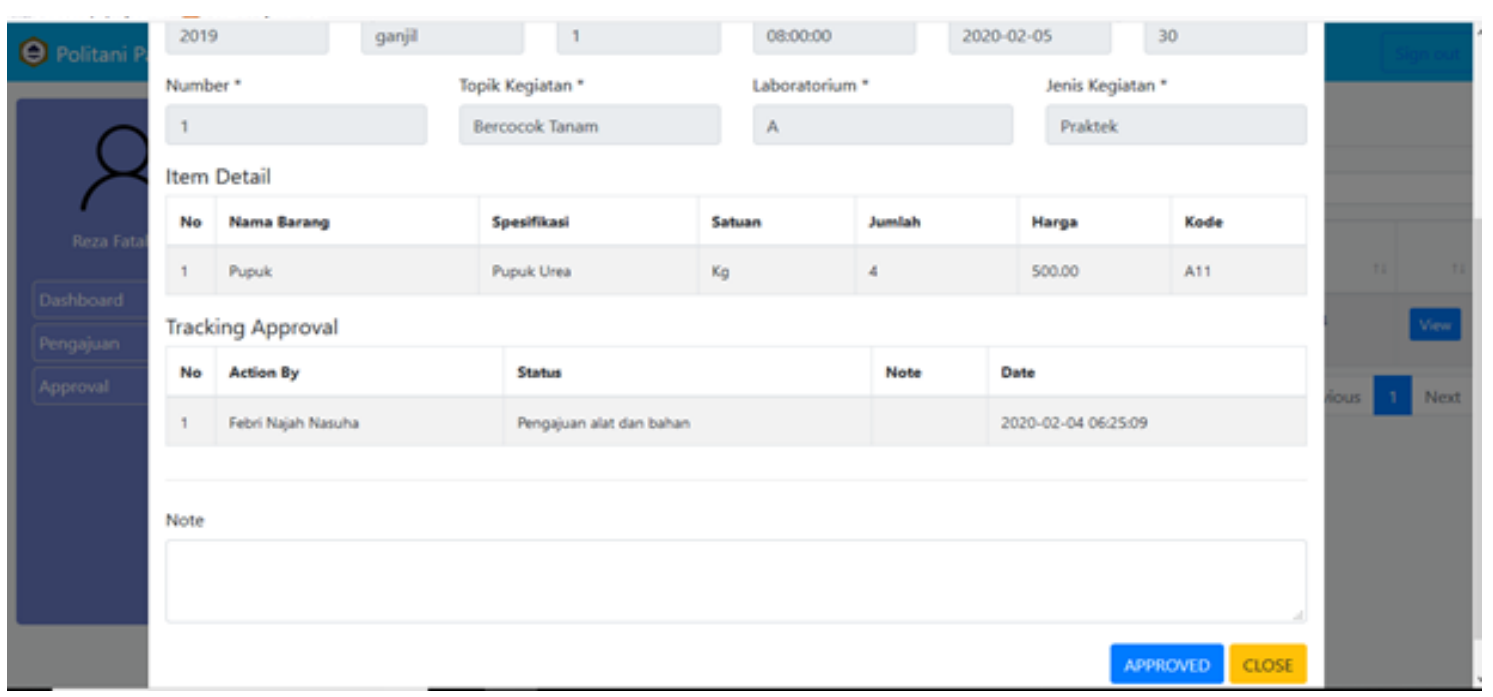

Gambar 13. Tampilan Form Approval 
d. Form Approval/Reject

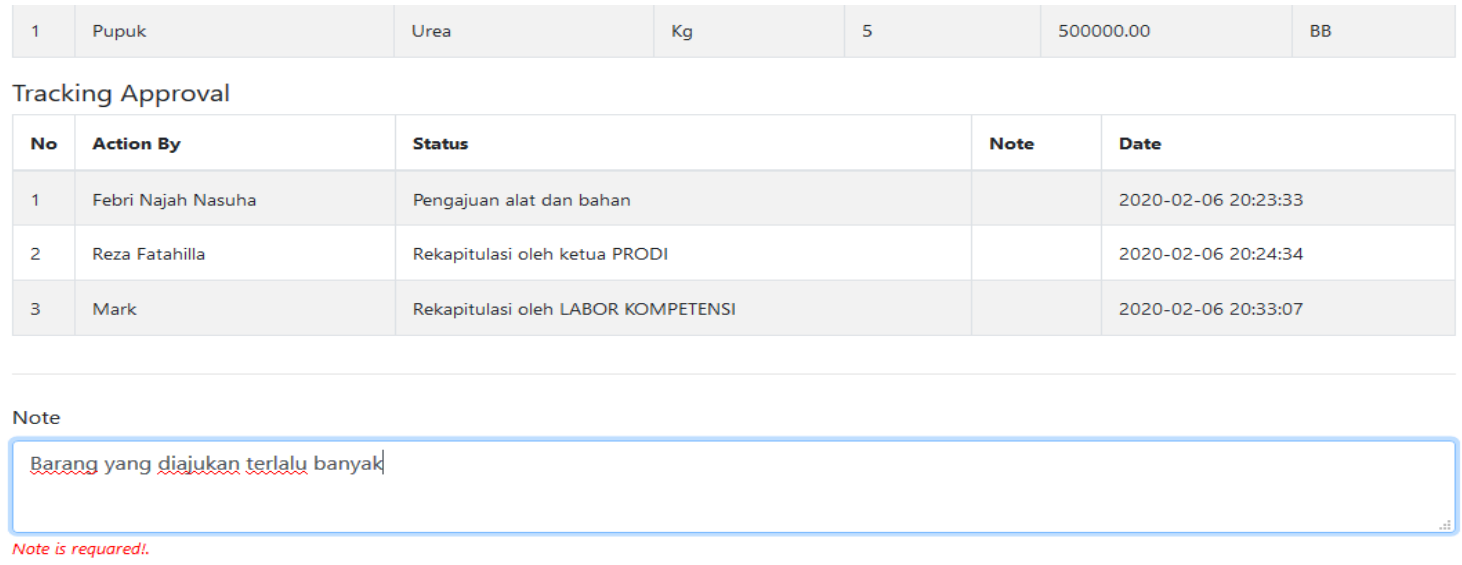

\section{Gambar 14. Tampilan Form Approval / Reject}

7. Cetak Laporan / Report

Dalam hal untuk mencetak Laporan hanya dapat dilakukan oleh satu Account, yaitu hanya bagian Pengadaan saja..Setelah semua proses pengajuan Alat dan Bahan Praktek telah Di Acc maka bagian Pengadaan akan mempersiapkan semua Alat dan bahan Praktek, dengan merekap terlebih dahulu semua daftar ajuan.

a. List yang dicetak

\section{$\Theta$ Politani Payakumbuh}
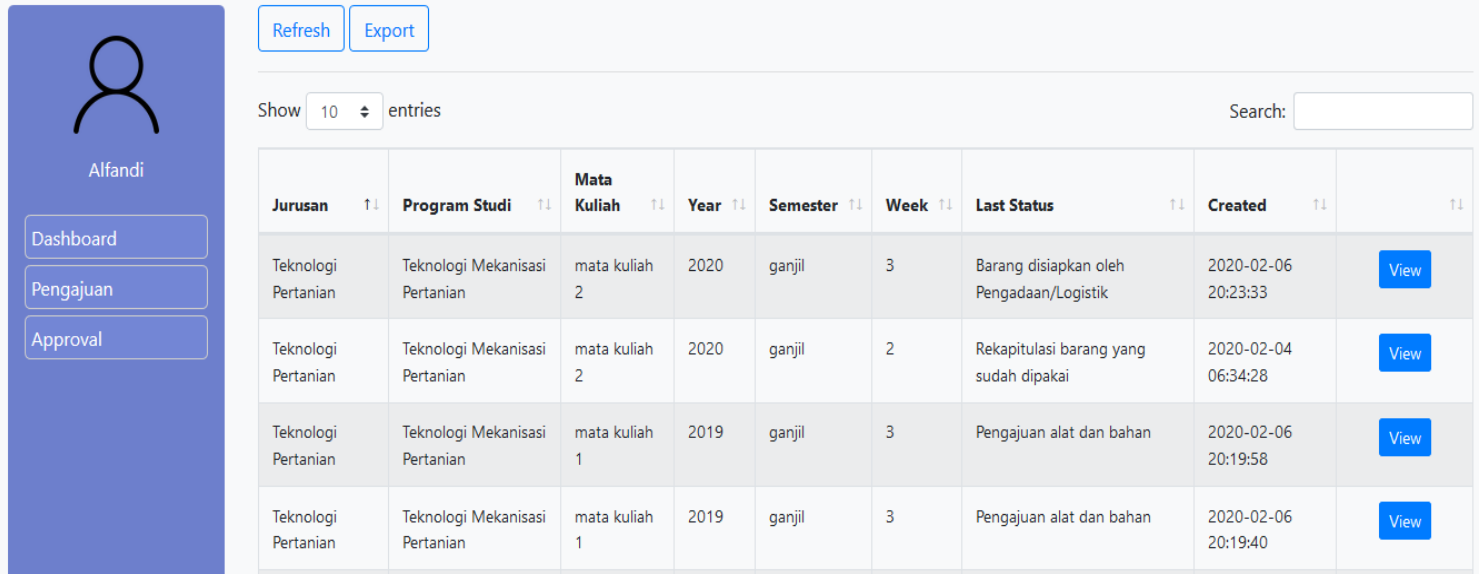

Gambar 15. Tampilan List yang Dicetak 
b. Detail List Laporan yang Akan Dicetak

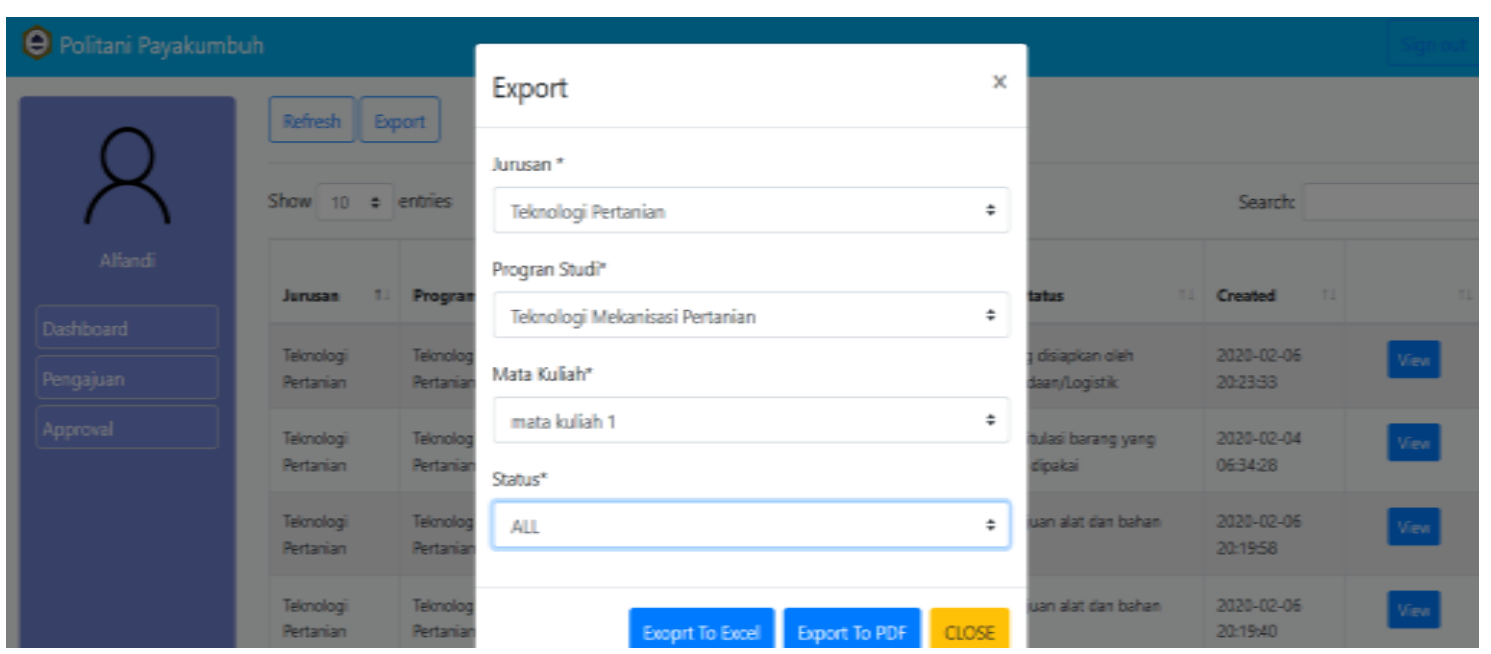

Gambar 16. Tampilan List Laporan yang Akan Dicetak

c. Laporan yang akan dicetak

\begin{tabular}{|c|c|c|c|c|c|c|c|c|c|c|c|c|c|}
\hline Punzan & Program Studi & Mata Kuiah & Trahur & Emostor & Minggu Kn & $\begin{array}{l}\text { Jumlahh } \\
\text { Mahasiswas }\end{array}$ & Nomor & Tangyal & lam & anboratorium & Peris Kngiatar & Trapik Kngagatan & Sithus \\
\hline $\begin{array}{l}\text { Toknologi } \\
\text { Pertarian }\end{array}$ & $\begin{array}{l}\text { Toknologi } \\
\text { Pakanaissasi } \\
\text { Pertarian }\end{array}$ & manta kuliah 1 & 019 & |annili & & $e^{5}$ & & $2020-02-06$ & 99000000 & & Prakkikum & Parmupukan & $\begin{array}{l}\text { Pongajuan allat } \\
\text { anan bahan }\end{array}$ \\
\hline \begin{tabular}{|l|l|} 
Taknologi \\
Pertanian
\end{tabular} & $\begin{array}{l}\text { Toknologi } \\
\text { Pakannisnsi } \\
\text { Pertanian }\end{array}$ & nnata kuliah 1 & 019 & panjiil & & $p^{5}$ & & $0020-02-06$ & 9900000 & & Praktikum & Pomupukan & $\begin{array}{l}\text { Pangajuan allat } \\
\text { tan bahan }\end{array}$ \\
\hline $\begin{array}{l}\text { Toknologi } \\
\text { Pertarian }\end{array}$ & $\begin{array}{l}\text { Toknnologi } \\
\text { Makanisasi } \\
\text { Pertaniann }\end{array}$ & mata kuliah 1 & 2019 & parriil & & $p^{5}$ & & $0020-02-06$ & p9:00:00 & & Praktikum & Permıpukan & $\begin{array}{l}\text { Engajuan alat } \\
\text { tan bahann }\end{array}$ \\
\hline \begin{tabular}{|l|} 
Teknologi \\
Pertarian
\end{tabular} & $\begin{array}{l}\text { Teknologi } \\
\text { Nekanisasi } \\
\text { Pertarian }\end{array}$ & nrata kuliah 1 & 2019 & |arriil & & 25 & & $2020-02-06$ & pa:00:00 & & Prakkikum & Pemuppukan & 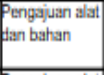 \\
\hline $\begin{array}{l}\text { Teknologi } \\
\text { pertarian }\end{array}$ & $\begin{array}{l}\text { Teknologi } \\
\text { Mekanisasi } \\
\text { Pertanian }\end{array}$ & matata kuliah 1 & 2019 & |zariil & & 25 & & $2020-02-06$ & pa:00:00 & & Prakkikum & Permupukan & 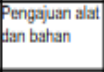 \\
\hline $\begin{array}{l}\text { Eeknolggi } \\
\text { Pertarian }\end{array}$ & $\begin{array}{l}\text { Teknologi } \\
\text { Mekanisasi } \\
\text { Pertanian }\end{array}$ & matata kuliah 1 & 2019 & |jariil & & 25 & & $2020-02-06$ & p9:00:00 & 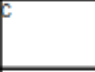 & Prakikimum & Permupukan & 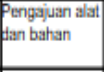 \\
\hline $\begin{array}{l}\text { Teknologi } \\
\text { Pertarian }\end{array}$ & $\begin{array}{l}\text { TEknologi } \\
\text { Nekanisasi } \\
\text { Eetranian }\end{array}$ & matata kuliah 1 & 2019 & |arriil & & 25 & & $2020-02-08$ & 99000.00 & & Prakkikum & Permupukan & 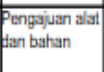 \\
\hline $\begin{array}{l}\text { Teknologi } \\
\text { Pertarian }\end{array}$ & $\begin{array}{l}\text { Teknologi } \\
\text { Pekanisasi } \\
\text { Pertarian }\end{array}$ & matata kuliah 1 & 2019 & |arniil & & po & & $2020-02-05$ & $80.00: 00$ & & Prakitiok & $\begin{array}{l}\text { Bercocock } \\
\text { Tannam }\end{array}$ & $\begin{array}{l}\text { Penggunaan } \\
\text { tat dan bahan }\end{array}$ \\
\hline $\begin{array}{l}\text { Teknologi } \\
\text { pertarian }\end{array}$ & $\begin{array}{l}\text { Teknologi } \\
\text { Mekanisasi } \\
\text { Pertaniann }\end{array}$ & matata kuliah 1 & 2020 & |jariil & & 20 & & $2020-01-05$ & p7:00:00 & abor $\mathrm{A}$ & apangan & prakkikum & 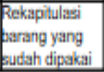 \\
\hline
\end{tabular}

Gambar 17. Tampilan Laporan yang Akan Dicetak

\section{KESIMPULAN}

Sistem ini dibangun untuk mempercepat serta mempermudah proses pengajuan alat dan bahan praktek pada Politeknik Pertanian Negeri Payakumbuh. Dalam Pembuatan system pengelolaan alat dan bahan praktek ini dibuat dengan menggunakan bahasa pemrograman PHP sehingga memudahkan user untuk mengakses sistem. Dengan cara menggunakan aplikasi MySQL sebagai database server, memudahkan dalam mengakses data. 


\section{SARAN}

Sistem Informasi pengelolaan alat dan bahan praktek ini masih perlu pengembangan lebih lanjut seperti penambahan fitur - fitur lain yang lebih banyak. Pada sistem informasi pengelolaan alat dan bahan praktek yang dibuat saat ini hanya tertuju pada alat dan bahan yang sudah tersedia saja, mungkin untuk kedepannya dapat dikembangkan lagi untuk menu baru apabila barang yang diajukan tidak tersedia dan bagaimana solusinya.

\section{UCAPAN TERIMA KASIH}

Terima kasih Penulis ucapkan kepada Politeknik Pertanian Negeri Payakumbuh yang sudah bersedia memberikan izin kepada penulis untuk melakukan penelitian. Terima kasih juga penulis sampaikan kepada Universitas Gunadarma beserta dosen - dosennya yang telah memberikan bimbingan kepada penulis dalam proses penelitian ini. Dan terkhusus terima kasih penulis ucapkan kepada pihak keluarga yang telah memberi support dan dukungan finansial terhadap penulis, sehingga penelitian ini dapat berjalan dengan lancar.

\section{DAFTAR PUSTAKA}

[1] Al-Bahra. 2005, Analisis dan Desain Sistem Informasi, Graha Ilmu. Yogyakarta.

[2] Andri Kristanto. 2008, Perancangan Sistem Informasi dan Aplikasinya, Gava Media, Yogyakarta.

[3] Hamilton, Kim \& Russel Miles. 2006, "Learning UML 2.0”, O"Reilly Media.

[4] Hirin, A. M. \& Virgi. 2011, Cepat Mahir Pemrograman Web Dengan PHP dan MySQL (Level Dasar Sampai Mahir), PT Prestasi Pustakaraya, Jakarta.

[5] Jogiyanto, HM. 2005, Analisis dan Desain Sistem Informasi: Pendekatan Terstruktur Teori dan Praktik Aplikasi Bisnis, Andi, Yogyakarta.

[6] Kadir, Abdul. 2013, Pemrograman Database MySQL Untuk Pemula, Mediakom, Yogyakarta.

[7] Kristanto, Harianto. 2004, Konsep dan Perancangan Database, Andi, Yogyakarta.

[8] Nugroho, Adi. 2005, "Rational Rose Untuk Permodelan Berorientasi Objek", Informatika, Bandung.

[9] Sugianto. 2015, "Metode Penelitian Manajemen," Alfabeta, Bandung.

[10] Virgi, Hirin. 2011, Cepat Mahir Pemrograman Web Dengan PHP dan MySQL. PT Prestasi Pustakaraya, Jakarta. 